\title{
PERFIL DOS TUTORES DE GATOS E ASPECTOS RELACIONADOS À SUA CRIAÇÃO
}

\section{Fernanda de Fátima Zanon NOLÊTO, Veluma Aparecida Zanon NOLÊTO, Marcela Lichotti Carneiro RIBEIRO, Flávia Regina Cruz DIAS \& Denise Aparecida da SILVA*}

Universidade Iguaçu, Campus V - Itaperuna, Rio de Janeiro, Brasil.

*Autor para correspondência: cepe-facbs@ campus5.unig.br

DOI: http://dx.doi.org/10.18571/acbm.124

\section{RESUMO}

Uma pesquisa foi realizada no dia da campanha da vacinação antirrábica no mês de outubro de 2015 no município de Itaperuna - R.J., com o objetivo de avaliar o perfil dos tutores de gatos e aspectos relacionados à sua criação. No total foram entrevistados 48 tutores de gatos sendo a maioria $(47,91 \%)$ classificada como $\mathrm{C} 2$ de acordo com o nível socioeconômico e com ensino fundamental completo $(35,41 \%)$. O número de pessoas na família variou de duas a sete com média de 3,72 pessoas/família. Um total de $27,08 \%$ dos tutores possui apenas gatos e $72,91 \%$ também possuem cães. Em relação ao número de gatos/tutor, os resultados variaram de um a seis, com média de 2,21 gatos/tutor, sendo 58,49\% machos e 41,51\% fêmeas. A idade da maioria $(49,05 \%)$ era dois anos. No total 83,96\% dos gatos eram sem raça definida (SRD), 14,15\% da raça Siamês, 0,94\% Angorá e 0,94\% Persa, sendo $79,25 \%$ não esterilizados. No total, $50 \%$ dos tutores afirmaram que não permitem que o animal fique no interior da residência e, dentre os que permitem, 54,17\% afirmaram que o animal pode dormir em sua cama. Um total de $68,75 \%$ afirmou que já teve algum gato que por algum motivo sumiu e nunca mais voltou. Quanto ao motivo que levou a aquisição do gato, 41,66\% dos tutores afirmaram afeição e 37,5\% afirmou que o ambiente familiar melhorou após sua aquisição, no entanto, a maioria não observou melhora. As principais características dos felinos relatadas pelos tutores foram independência $(43,75 \%)$ e que são carinhosos $(31,25 \%)$.

Palavras-chave: Gatos; Criação; Tutores; Esterilização.

\begin{abstract}
A survey was carried out on the day of the rabies vaccination campaign in the month of October of 2015 in the city of Itaperuna - R.J., in order to evaluate the profile of the tutors of cats and aspects related to their creation. In total, 48 tutors of cats were interviewed, with the majority (47.91\%) classified as C2 according to the socioeconomic level and with complete elementary education (35.41\%). The number of people in the family ranged from two to seven with an average of 3.72 people / family. A total of $27.08 \%$ of tutors have only cats and $72.91 \%$ also have dogs. Regarding the number of cats / tutor, the results ranged from one to six, with a mean of 2.21 cats / tutors, being $58.49 \%$ males and $41.51 \%$ females. The age of the majority (49.05\%) was two years. A total of $83.96 \%$ of the cats were of undefined race (SRD), $14.15 \%$ Siamese, $0.94 \%$ Angora and $0.94 \%$ Persian, being that $79.25 \%$ of which were not sterilized. In total, $50 \%$ of the tutors affirmed that they do not allow the animal to stay inside the residence and among those who allow, $54.17 \%$ stated that the animal can sleep in their bed. A total of $68.75 \%$ affirmed that they had already had some cat that for some reason disappeared and never returned. As for the reason that led to the acquisition of the cat, $41.66 \%$ of the tutors cited affection and $37.5 \%$ stated that the family environment improved after their acquisition, however, most did not notice improvement. The main characteristics of the felines reported by the tutors were independence (43.75\%) and that they are affectionate $(31.25 \%)$.
\end{abstract}

Keywords: Cats; Breeding; Tutors; Sterilization. 


\section{Introdução}

A criação de cães e gatos no meio domiciliar é comum no mundo todo tendo se intensificado a partir dos séculos XVI e XVII com a melhoria da qualidade de vida da população humana que possibilitou a criação de animais sem função econômica (THOMAS, 1988). Em uma pesquisa realizada de setembro de 2006 a setembro de 2009 no município de São Paulo visando a caracterização demográfica das populações de cães e gatos foi verificada a razão homem:cão equivalente a 4,34 e a razão homem:gato equivalente a 19,33. A população canina foi estimada em 2.507.401 e a felina em 562.965 (CANATTO et al., 2012). No interior do estado de São Paulo, um estudo realizado em 2001 com o objetivo de avaliar a população de cães e gatos por habitante apontou a relação cão/habitante de 1:4,0 e de gato/habitante de 1:16,4. (ALVES et al., 2005). A Organização Mundial de Saúde (OMS) estima que em países em desenvolvimento a proporção média entre cães e seres humanos seja de 1:10 a 1:7. No caso dos gatos, estes representam cerca de $20 \%$ da população canina (MAGNABOSCO, 2006). Fatores socioeconômicos tais como escolaridade e renda não estão correlacionados com a razão homem:gato (DIAS et al., 2004; ALVES et al., 2005).

Fica claro, portanto, que de acordo com a maioria dos inquéritos populacionais referentes a gatos, estes se apresentam em número inferior quando comparados aos cães. Curiosamente, acredita-se que os gatos tenham sido os primeiros animais adotados como companhia pelos egípcios, há cerca de 3.600 anos (LINSEELE et al., 2007). Ao se avaliar a origem do gato doméstico, datada em 9.500 anos a.C no sudeste Asiático, pode-se observar que tal animal provoca diferentes e abundantes concepções na humanidade, provavelmente, relacionadas ao seu comportamento, havendo ocasiões nas quais o gato é visto positiva e outras negativamente, o que leva a momentos de perseguição, maus tratos e morte destes animais (DRISCOLL et al., 2009). Estudo relacionado a mitos, rituais e representações referentes ao gato doméstico citam sua associação com bruxas e o gato preto com má sorte (MACHADO; PAIXÃO, 2014). No Brasil o gato preto é relacionado à prática de magia negra e associado à má sorte (OSÓRIO, 2011). O gato possui uma personalidade independente e peculiar que pode gerar comportamentos desagradáveis ou até mesmo incompatíveis com o tutor, o que contribui para o abandono (FARIA et al., 2013). Episódios de maus tratos são comuns em gatos e abrangem tortura tais como, atear fogo no animal, deixar o mesmo morrer de fome, colocá-lo em um saco plástico e jogar em um rio, jogar o animal do alto de um edifício, armas de fogo, dentre outros (MERCK, 2013). Tipo bastante comum de maus tratos é o envenenamento com carbamatos (conhecido popularmente como "chumbinho") que ocorre de maneira premeditada através de sua adição ao alimento oferecido ao animal (XAVIER et al., 2007; MEDEIROS et al., 2009; BULCÃO et al., 2010; SIQUEIRA et al., 2012). Os dois principais tipos de maus tratos aos gatos domésticos incluem o envenenamento intencional por pesticidas e traumas mecânicos (SIQUEIRA et al., 2013).

Outro aspecto considerado por grande parte da população e que colabora por denegrir a imagem dos gatos é a transmissão de doenças, em especial a toxoplasmose. A doença é de caráter zoonótico, causada pelo protozoário Toxoplasma gondii, e os felinos são considerados hospedeiros definitivos, podendo atuar como hospedeiros intermediários da doença (MARTINS; VIANA, 1998). No entanto, apesar do gato ser visto como o maior responsável pela transmissão do agente etiológico da toxoplasmose, uma das principais formas de infecção humana, considerando-se a transmissão pós-natal, ocorre através do consumo de carne crua ou mal cozida de bovinos e suínos contendo cistos, além da ingestão de água ou alimentos contaminados por oocistos (CADEMARTORI et al., 2012). Além disso, vale ressaltar que os quadros de toxoplasmose apresentam maior gravidade nos seres humanos ao se considerar a infecção aguda durante a gestação, pois $80 \%$ das infecções primárias por T. gondii no homem permanecem assintomáticas, devido à efetividade do sistema imune (CANTOS et al., 2000). 
Partindo-se para o campo afetivo e emocional, os gatos apresentam efeitos benéficos aos seres humanos, havendo estudos em idosos, principalmente, que afirmam apoio emocional nos animais, diminuição da pressão arterial e riscos de problemas cardíacos, estimulação da memória, com melhora na qualidade de vida, suprindo a escassez de afeto nesta etapa da vida. Os idosos sentem-se importantes e úteis, preservando sua saúde física e mental, adoecendo menos e diminuindo a probabilidade de apresentar depressão (PEREIRA; WENDT, 2009).

Tendo em vista a importância sobre a conscientização sobre o aspecto disseminador da toxoplasmose, sendo o gato não o grande vilão e os benefícios causados pelos gatos na população, principalmente na população senil, este estudo apresentou como objetivo a obtenção de informações sobre o perfil dos proprietários e os aspectos domiciliares dos gatos.

\section{Metodologia}

A pesquisa foi realizada no dia da campanha da vacinação antirrábica no mês de outubro de 2015 no município de Itaperuna, estado do Rio de Janeiro. Trata-se de pesquisa quantitativa e qualitativa através de questionário semiestruturado. Como forma de coleta de dados foi elaborada uma ficha contendo um questionário com dados referentes ao animal (idade, sexo, raça) bem como outras informações tais como: forma de aquisição do animal, se o animal em questão foi submetido ao método de esterilização, hábitos do animal, local de manutenção do animal, quantidade de gatos presentes na residência, característica mais peculiar do felino, se tem conhecimento sobre toxoplasmose e motivos para ter adquirido o animal. Especificamente sobre o proprietário/tutor, seu nível socioeconômico e escolaridade. Previamente à coleta das informações, foi disponibilizado aos tutores o Termo de Consentimento Livre e Esclarecido - TCLE (OLIVEIRA et al., 2010). Os resultados foram avaliados através de estatística descritiva (SILVESTRE, 2007).

\section{Resultados}

No total foram entrevistados 48 tutores de gatos sendo 15 (31,25\%) classificados como C1 conforme o nível socioeconômico, 23 (47,91\%) classificados como C2 e 10 (20,83\%) classificados como D (Figura 1).

Quanto à escolaridade, verificou-se que sete são analfabetos (14,58\%), 13 possuem ensino fundamental incompleto $(27,08 \%), 17$ possuem ensino fundamental completo $(35,41 \%)$, seis possuem ensino médio completo $(12,5 \%)$ e cinco $(10,41 \%)$ possuem ensino médio incompleto. $\mathrm{O}$ número de pessoas na família variou de duas a sete com média de 3,72 pessoas/família. Dentre o total de tutores, 13 afirmaram que possuem apenas gatos $(27,08 \%)$ e 35 também possuem cães (72,91\%), conforme figura 2.

Em relação ao número de gatos/tutor, os resultados variaram de um a seis gatos, com média de 2,21 gatos/tutor. Ao se avaliar o sexo dos gatos, $62(58,49 \%)$ eram machos e $44(41,51 \%)$ fêmeas, totalizando 106 gatos entre todos os tutores questionados (Figura 3). 


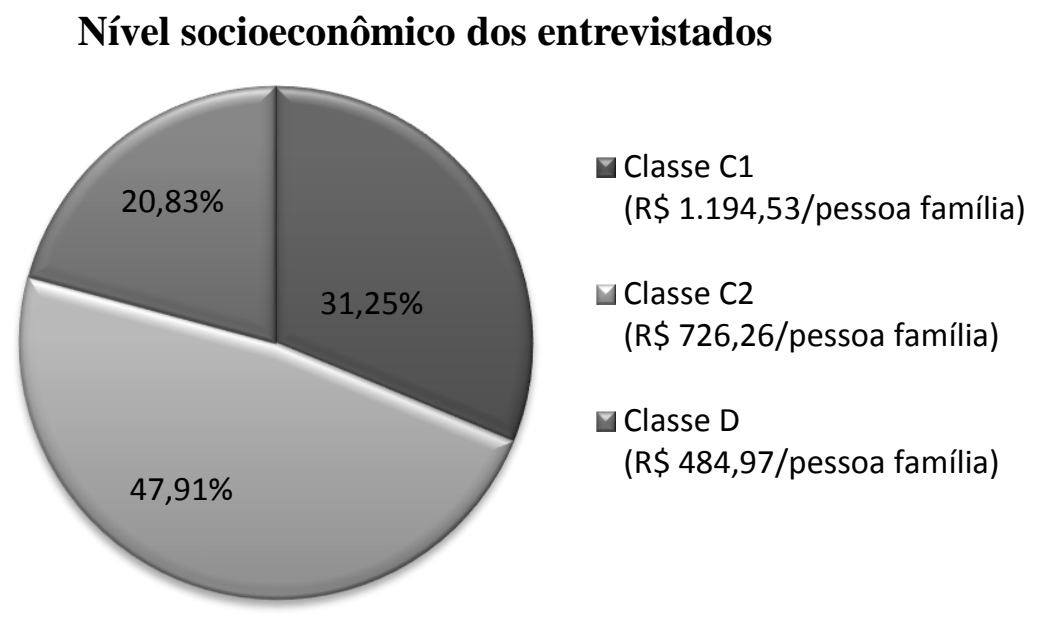

Figura 1: Classificação dos tutores de gatos de acordo com o nível socioeconômico conforme pesquisa realizada durante campanha de vacinação antirrábica no município de Itaperuna - RJ, no ano de 2015.

\section{Tutores que possuem cães e/ou gatos}

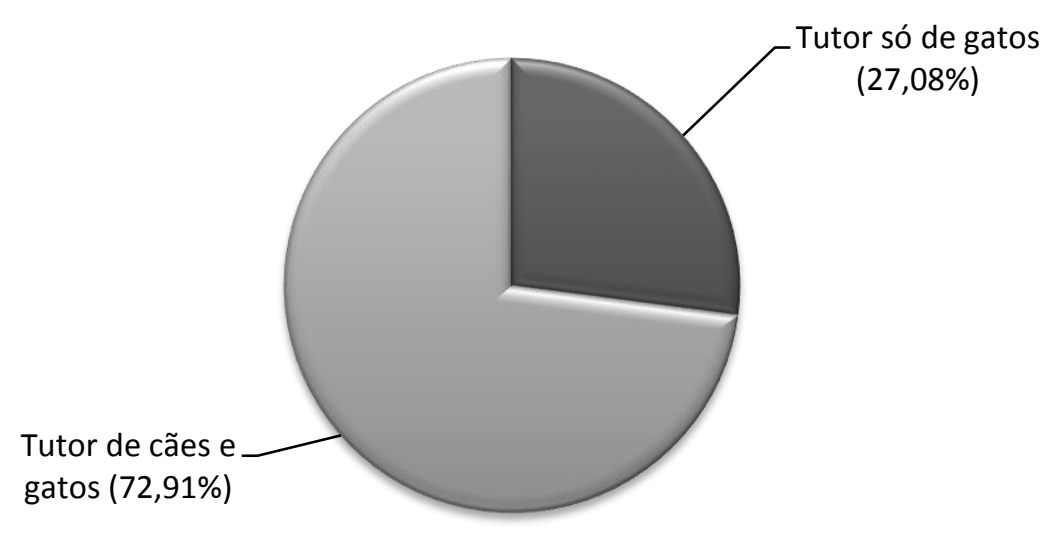

Figura 2: Percentual de tutores apenas de gatos ou de cães e gatos conforme pesquisa realizada durante campanha de vacinação antirrábica no município de Itaperuna - RJ, no ano de 2015.

Foram avaliadas as idades dos gatos, sendo que $10(8,49 \%)$ apresentavam até 11 meses de idade, $21(19,81 \%)$ com um ano de idade, $52(49,05 \%)$ com dois anos, $10(9,43 \%)$ apresentando três anos de idade, um $(0,94 \%)$ com quatro anos, cinco $(4,71 \%)$ com cinco anos, cinco $(4,71 \%)$ com seis anos e, no caso de dois gatos $(1,88 \%)$ o tutor não soube informar ao certo a idade do animal (Tabela 1). 


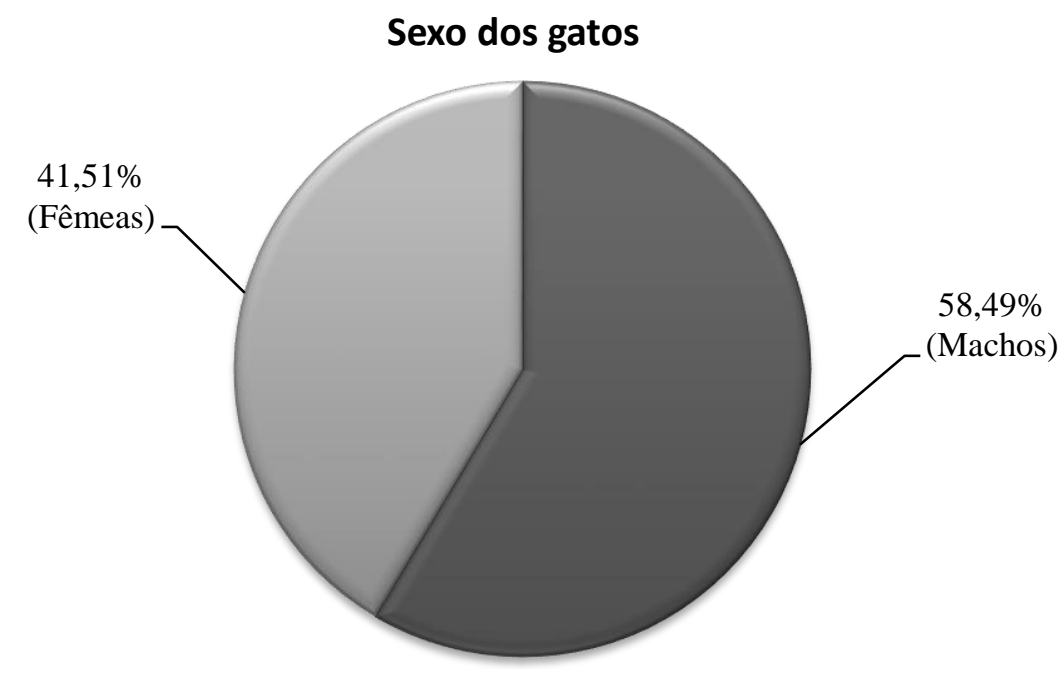

Figura 3: Percentual de gatos de acordo com o sexo conforme pesquisa realizada durante campanha de vacinação antirrábica no município de Itaperuna - RJ, no ano de 2015.

Tabela 1: Percentual de gatos de acordo com a idade conforme pesquisa realizada durante campanha de vacinação antirrábica no município de Itaperuna - RJ, no ano de 2015.

\begin{tabular}{cc}
\hline Idade & Número de gatos (\%) \\
\hline$<11$ meses & $10(9,43 \%)$ \\
1 ano & $21(19,81 \%)$ \\
2 anos & $52(49,05 \%)$ \\
3 anos & $10(9,43 \%)$ \\
4 anos & $01(0,94 \%)$ \\
5 anos & $05(4,71 \%)$ \\
6 anos & $05(4,71 \%)$ \\
Não soube informar & $02(1,88 \%)$ \\
\hline
\end{tabular}

Considerando-se a raça dos animais, foi observado um total de 89 gatos $(83,96 \%)$ sem raça definida (SRD), 15 gatos da raça Siamês $(14,15 \%)$, um $(0,94 \%)$ da raça Angorá e um $(0,94 \%)$ da raça Persa (Figura 4).

\section{Raça dos gatos}

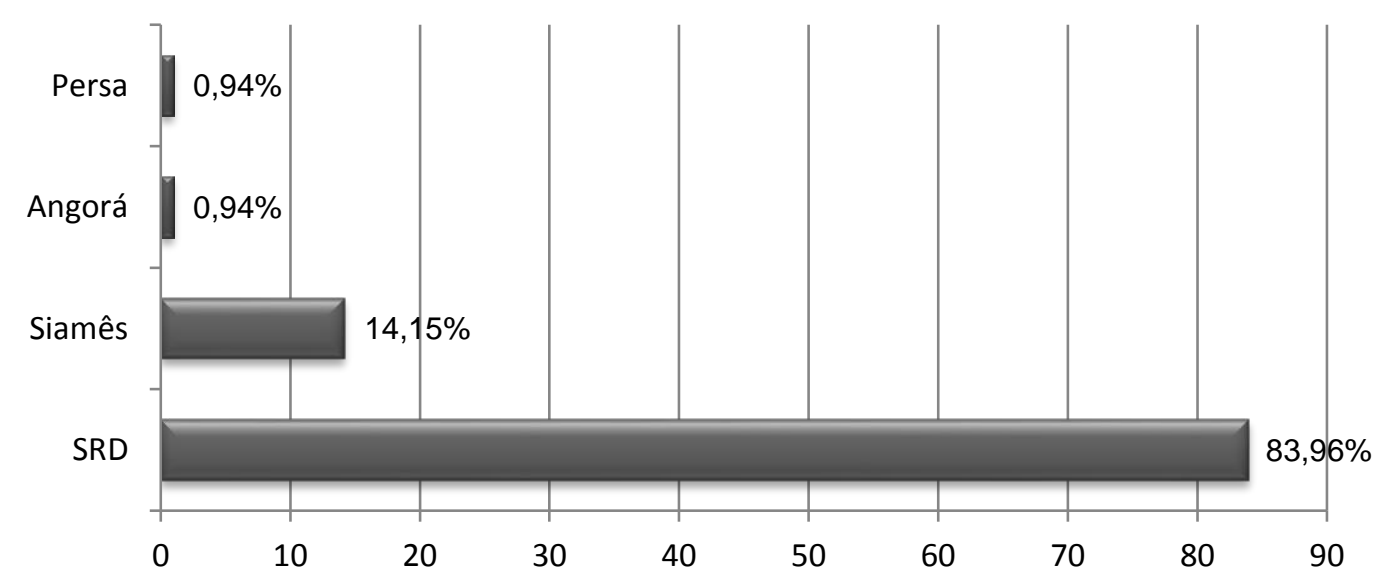

Figura 4: Percentual de gatos de acordo com a raça conforme pesquisa realizada durante campanha de vacinação antirrábica no município de Itaperuna - RJ, no ano de 2015. 
Dentre os animais avaliados, $22(20,75 \%)$ são esterilizados e $84(79,25 \%)$ não são. Avaliando-se conforme o sexo, sete machos e 15 fêmeas são castrados, perfazendo 11,29\% e $34,09 \%$ dos machos e fêmeas, respectivamente (Figura 5).

\section{Número de gatos esterilizados/sexo}

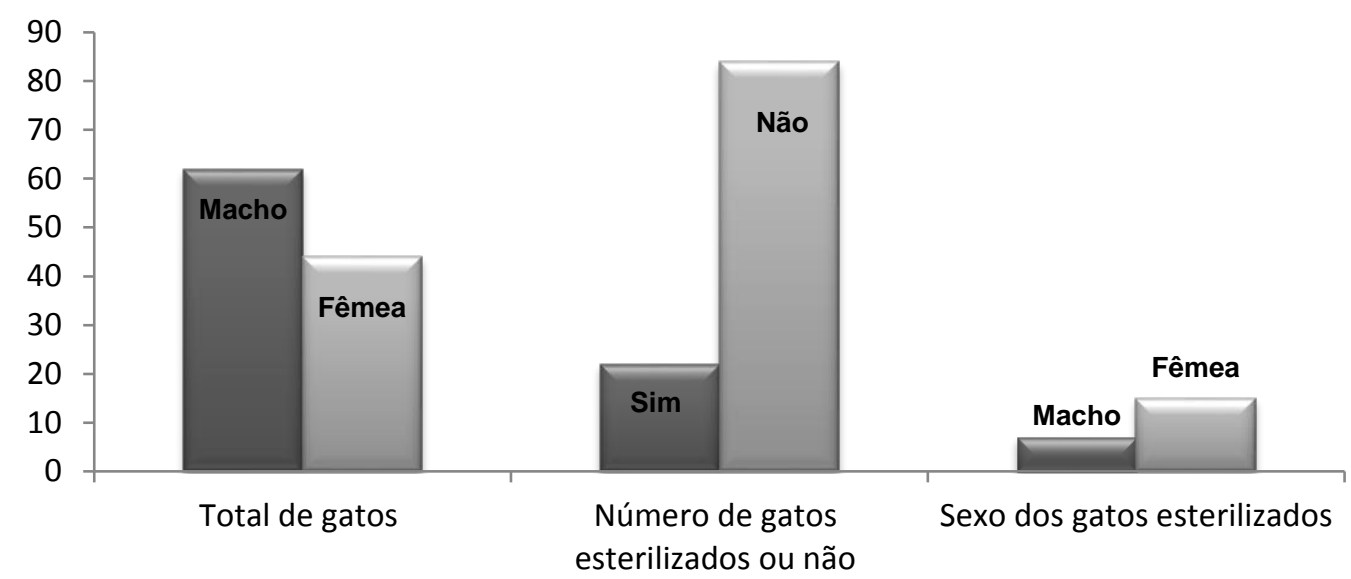

Figura 5: Número de gatos esterilizados em relação ao total e de acordo com o sexo, conforme pesquisa realizada durante campanha de vacinação antirrábica no município de Itaperuna - RJ, no ano de 2015.

Ao serem indagados sobre os hábitos na criação dos gatos dentro de casa, 24 tutores $(50 \%)$ afirmaram que não permitem que o animal fique no interior da residência e, dentre os que permitem, um total de $13(54,17 \%)$ afirmou que o animal pode dormir em sua cama.

Um total de 33 tutores $(68,75 \%)$ afirmou que já teve algum gato que por algum motivo sumiu e nunca mais voltou, enquanto que 15 tutores $(31,25 \%)$ nunca apresentaram tal problema. Em relação aos animais dos quais cuidavam no momento da pesquisa, 22 tutores relataram que já haviam fugido $(45,83 \%)$ e $26(54,16 \%)$ afirmaram o gato nunca fugiu. Dentre os que afirmaram que o gato nunca fugiu, em nove casos os animais eram castrados $(34,62 \%)$, sendo que sete tutores afirmaram que o animal já havia fugido, porém, depois de castrados não aconteceu novamente.

Ao serem questionados se alguém da família não apreciava gatos, 16 tutores $(33,33 \%)$ afirmaram que sim e $32(66,66 \%)$ responderam que não. Ainda em relação ao ambiente familiar $\mathrm{X}$ gato, foi perguntado se algum membro da família apresenta alergia aos pelos do gato e, 45 tutores afirmaram que não $(93,75 \%)$ contra três $(6,25 \%)$ que responderam que sim.

Quanto ao motivo que levou a aquisição do gato, 20 tutores $(41,66 \%)$ afirmaram afeição pelos de gatos, nove $(18,66 \%)$ encontraram o animal na rua, seis $(12,5 \%)$ possuem gatos com o intuito de caçar ratos, três $(6,25 \%)$ alegaram que algum membro da família pediu como animal de estimação, sete $(14,58 \%)$ ganharam de algum amigo, um $(2,08 \%)$ relatou que a mãe já habitava na residência e ele ficou com o filhote, um $(2,08 \%)$ relatou que o gato apareceu no domicílio e um $(2,08 \%)$ mora em apartamento e alega ter mais praticidade em se ter um gato como animal de estimação (Tabela 2). 
Tabela 2: Motivos que levaram à criação do(s) gato(s), conforme pesquisa realizada durante campanha de vacinação antirrábica no município de Itaperuna - RJ, no ano de 2015.

\begin{tabular}{cc}
\hline Motivos & Número de tutores $(\%)$ \\
\hline Afeição por gatos & $20(41,66 \%)$ \\
Encontrou na rua & $09(18,66 \%)$ \\
Para caçar ratos & $06(6,25 \%)$ \\
Membro da família pediu & $03(9,43 \%)$ \\
Presente de um amigo & $07(14,58 \%)$ \\
Nasceu na residência & $01(2,08 \%)$ \\
Apareceu na residência & $01(2,08 \%)$ \\
Reside em apartamento & $01(2,08 \%)$ \\
\hline
\end{tabular}

Após a aquisição do gato foi questionado se o ambiente familiar melhorou e do total dos entrevistados $18(37,5 \%)$ tiveram uma impressão positiva enquanto que $30(62,5 \%)$ alegaram que nada mudou (Figura 6).

\section{Houve mudança no ambiente familiar com a aquisição do gato?}

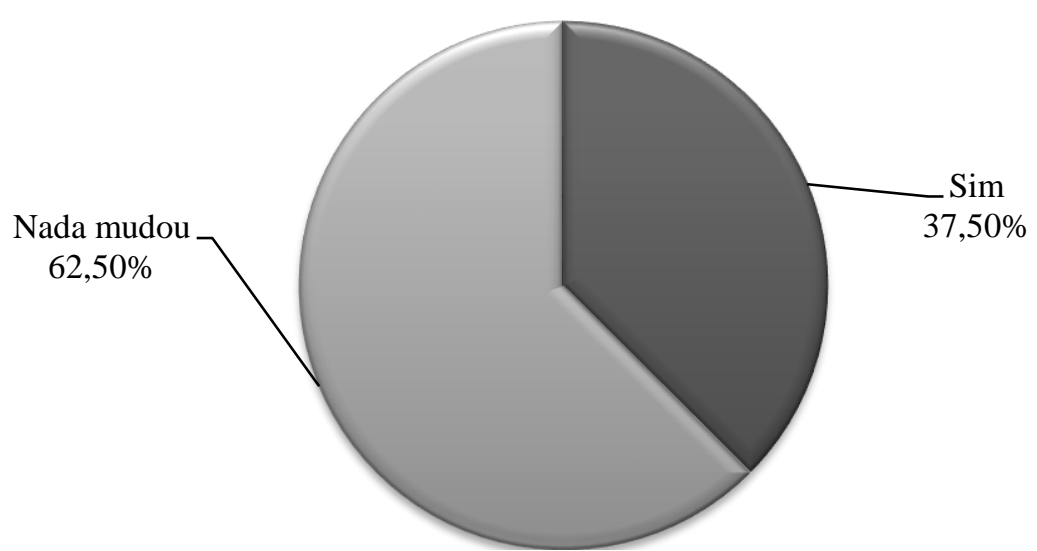

Figura 6: Resposta dos tutores ao serem indagados sobre mudança no ambiente familiar após aquisição do gato, conforme pesquisa realizada durante campanha de vacinação antirrábica no município de Itaperuna - RJ, no ano de 2015.

Quanto à dificuldade na criação de gatos, 45 tutores afirmaram que não é difícil $(93,75 \%)$ e três $(6,25 \%)$ consideram difícil sua criação.

Ao serem questionados sobre o conhecimento acerca da toxoplasmose nos gatos, 26 tutores afirmaram ter algum conhecimento $(54,17 \%)$ e $22(45,83 \%)$ não sabem nada a respeito (Figura 7$)$. $\mathrm{E}$, ainda, três tutores $(6,25 \%)$ afirmaram que já contraíram a doença.

Em relação às principais características dos felinos relatadas pelos tutores, 21 se referiram à independência de tais animais (43,75\%), 15 citaram que são animais carinhosos $(31,25 \%)$, sete $(14,58 \%)$ afirmaram que são bons caçadores, dois $(4,17 \%)$ que são animais limpos e não requerem atenção para sua higienização, um tutor $(2,08 \%)$ citou que a criação não requer gasto financeiro significativo, um $(2,08 \%)$ relatou o hábito dos gatos de brincarem com objetos, uma característica que transmite felicidade, um tutor (2,08\%) citou que não precisa dar ração (Figura 8). 


\section{Conhecimento do tutor sobre Toxoplasmose}

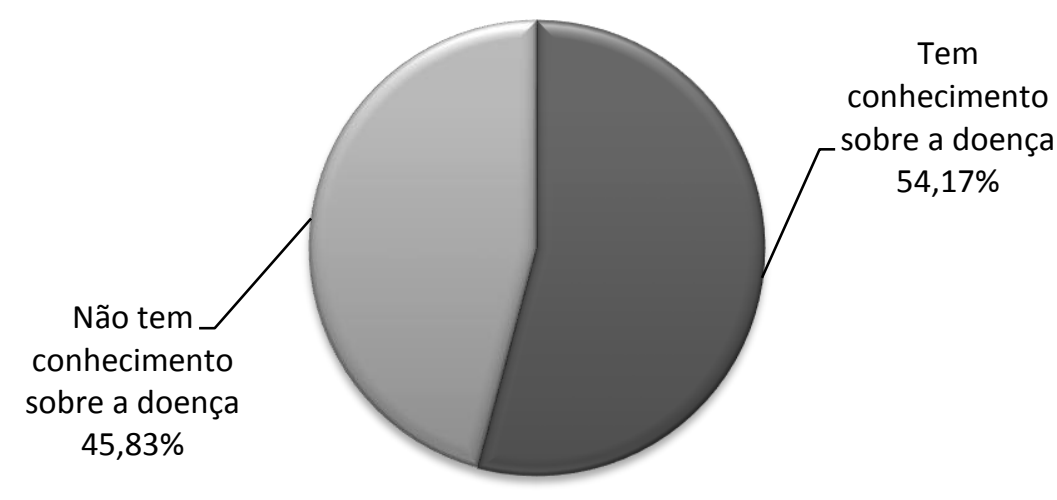

Figura 7: Percentual de tutores de gatos que apresenta ou não conhecimento acerca da toxoplasmose, conforme pesquisa realizada durante campanha de vacinação antirrábica no município de Itaperuna - RJ, no ano de 2015.

\section{Pincipais cracterísticas dos felinos conforme os tutores}

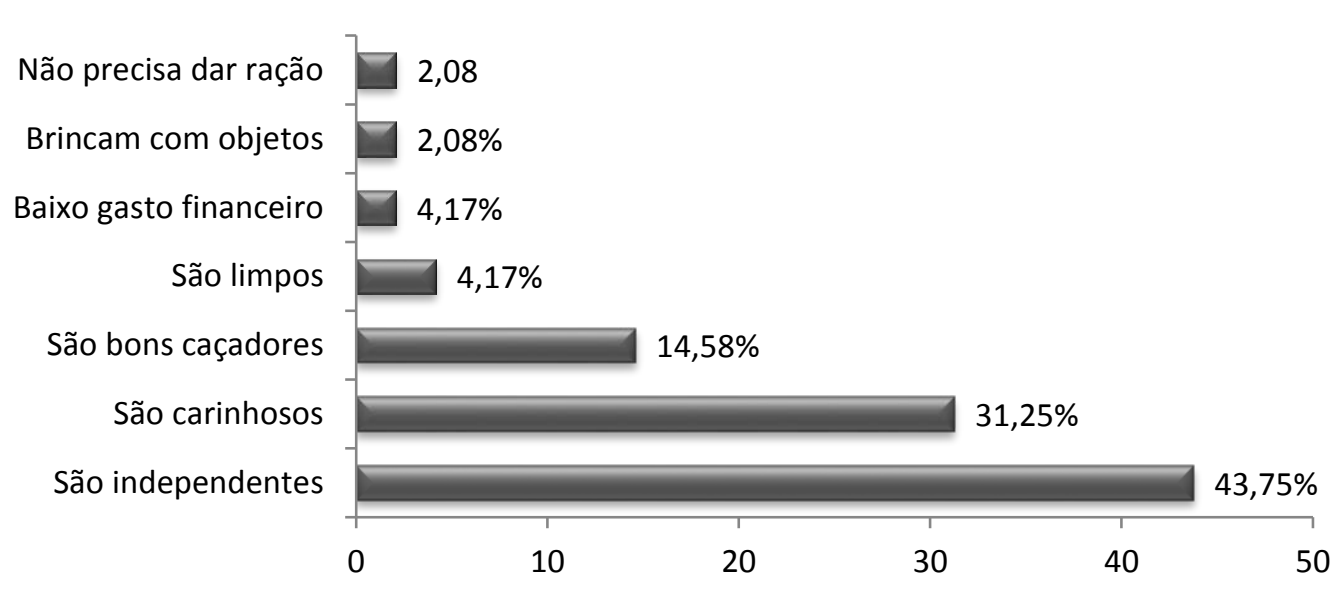

Figura 8: Principais características dos felinos citadas pelos tutores de gatos, conforme pesquisa realizada durante campanha de vacinação antirrábica no município de Itaperuna - RJ, no ano de 2015.

\section{Discussão}

De acordo com os resultados, foi possível observar que a totalidade dos tutores de gatos encontra-se classificada, conforme o nível socioeconômico, como C e D, sendo que os tutores que apresentam o maior número de gatos, no caso dois tutores com seis gatos cada, incluem-se na classe D. Tal resultado sugere que possa haver correlação entre a renda e o número de gatos, porém, deve-se também considerar que se trata de uma campanha do município, portanto gratuita, a qual é mais procurada realmente pelos proprietários ou tutores de menor renda. Mais de $70 \%$ dos tutores de gatos também criam cães, o que denota a afeição dos proprietários pelos animais de pequeno porte de modo geral e, até mesmo a preferência pelos cães, uma vez que já se sabe que a 
população de gatos é inferior à de cães no Brasil e que representa cerca de $20 \%$ da população canina (MAGNABOSCO, 2006).

A relação entre o número de machos e fêmeas foi bem próxima, porém com número superior de machos. Geralmente, as fêmeas, em especial de gatos, são preteridas devido à dificuldade de controle em sua procriação, fazendo-se necessária sua esterilização, a qual demanda gastos e cuidados durante o período pós-operatório. De qualquer maneira, o número de fêmeas foi superior ao esperado, o que significa que os tutores não estão considerando o problema citado. A menor idade observada foi de quatro meses, no entanto, havia animais com oito e nove meses ainda não vacinados, ou seja, apesar da vacinação ser indicada aos quatro meses, muitos tutores optam pela espera da campanha municipal. A maior idade observada foi seis anos, o que indica a dificuldade na criação da espécie em questão, pois apresentam maior longevidade, no entanto são comuns os casos de gatos que desaparecem, o que pode ser confirmado com os dados observados, uma vez que mais de $60 \%$ dos tutores afirmou já ter perdido algum gato devido a esse motivo. Os machos, mais frequentemente, tendem a realizar suas saídas, às vezes por dias, mantendo-se em áreas onde se encontram fêmeas no cio. Não raramente costumam retornar às suas casas, porém, são vulneráveis aos diversos maus tratos durante suas saídas além dos riscos de atropelamento e brigas com outros machos. Uma das formas de minimizar tal problema é através da castração do animal, o que foi confirmado segundo a informação de alguns tutores, ou seja, seu animal frequentemente ficava dias fora de casa, porém após a castração ele se tornou mais caseiro. Os dados demonstram, no entanto, que o principal motivo da castração se refere mesmo ao controle das gestações, reduzindo-se o número de filhotes, até pela dificuldade em encontrar tutores para gatos. Ainda assim, o número de fêmeas esterilizadas é baixo e não atinge nem $40 \%$ das fêmeas. De um modo geral, considerando-se machos e fêmeas, o número de animais castrados é baixo.

Apesar de $50 \%$ dos tutores apresentar o hábito de manter o animal dentro de casa, nem todos permitem que fiquem em suas camas, o que é bastante frequente em relação aos gatos, principalmente os de raça, o que foi também observado nesta pesquisa, ou seja, os da raça Siamês e Persa, relativamente à quantidade de gatos $\mathrm{SRD}$, são mantidos em maior percentual na cama de seus tutores. Menos de 50\% dos tutores de gatos os têm por afeição, confirmando ainda nos dias de hoje, a aversão pela espécie e sua associação com bruxas, com má sorte e prática de magia negra (OSÓRIO, 2011; MACHADO; PAIXÃ̃O, 2014). A percepção de melhora no ambiente familiar foi de quase $40 \%$, corroborando com as citações referentes aos efeitos benéficos de animais de estimação aos seres humanos. Quase a totalidade dos tutores afirmou a facilidade na criação de gatos, o que se justifica, provavelmente, pela independência da espécie, pois não despendem de muito tempo de seus tutores quanto à alimentação e mesmo em relação às necessidades fisiológicas. Curiosamente, apesar de maior facilidade em comparação aos cães, não são os preferidos, uma vez que carregam consigo o estigma já citado anteriormente e que suplanta inclusive as dificuldades de criação dos cães. O conhecimento sobre a toxoplasmose foi citado por mais de 50\% dos tutores, não representando, portanto, uma limitação para a criação da espécie.

A principal característica dos gatos foi independência, a qual está associada a vários pontos positivos da espécie como a facilidade na criação. Assim, o tutor busca aliar a criação de um animal de estimação à praticidade na sua criação de modo a não interferir nas suas atividades diárias. Estudos indicam que a personalidade independente e peculiar dos gatos é responsável também pelos comportamentos desagradáveis ou até mesmo incompatíveis com o tutor, contribuindo para o abandono (FARIA et al., 2013). Cerca de 30\% dos tutores citaram que os gatos são carinhosos. Vale ressaltar que os gatos não demonstram o carinho pelos seus tutores da mesma forma que os cães. Eles interagem com os humanos ronronando, esfregando a face em partes de seu tutor, subindo no colo em busca de afago, ficando próximo ao tutor, esfregando o corpo na mão de uma pessoa que não esteja interagindo com eles, rolando de um lado para o outro, mostrando a barriga (ELLIS et al., 2013). E todas estas manifestações de carinho são realizadas delicadamente e de forma comedida, podendo ser imperceptíveis para muitas pessoas. 


\section{Conclusões}

De acordo com a metodologia utilizada conclui-se que: a maioria dos tutores de gatos pertence às classes $\mathrm{C}$ e $\mathrm{D}$ conforme o nível socioeconômico, possui ensino fundamental completo e também cria cães; a média de gatos/tutor é de 2,21 sendo a maioria machos, com dois anos de idade e sem raça definida; a maioria dos gatos não é esterilizada e, dentre os esterilizados a maioria é de fêmeas; metade dos gatos têm acesso à parte interna da residência; a maioria dos tutores já teve algum gato que fugiu de casa; a maioria dos tutores adquiriu o gato por afeição à espécie; a maioria não observou melhora do ambiente familiar com a aquisição do gato; a principal característica dos gatos citada foi independência.

\section{Referências}

ALVES, M.C.G.P.; MATOS, M.R.; REICHMAN, M.L. et al. Dimensionamento da população de cães e gatos no interior do Estado de São Paulo. Rev. Saúde Publ., v. 39, p. 891-897, 2005.

BULCÃO, R.C., TONELLO, R.; PIVA, S.J. et al. Intoxicação em cães e gatos: diagnóstico toxicológico empregando cromatografia em camada delgada e cromatografia líquida de alta pressão com detecção ultravioleta em amostras estomacais. Ciência Rural, v. 40, n. 5, p. 1109$1113,2010$.

CADEMARTORI, B.G.; SANTOS, L.M.J.; QUEVEDO NETO, P.S. et al. Toxoplasma gondii diagnóstico sorológico e isolamento em suínos de criação artesanal no sul do Brasil - nota prévia. The Biologist, v. 10, n. 2, 2012.

CANATTO, B.D.; SILVA, E.A.; BERNARDI, F. et al. Caracterização demográfica das populações de cães e gatos supervisionados do município de São Paulo. Arq. Bras. Med. Vet. Zootec., v. 64, n. 6, p. 1515-1523, 2012.

CANTOS, G.A.; PRANDO, M.D.; SIQUEIRA, M.V. et al. Toxoplasmose: ocorrência de anticorpos anti-Toxoplasma gondii e diagnóstico. Revista Associação Médica Brasileira, v. 46, n. 4, p. 335-341, 2000.

DIAS, R.A.; GARCIA, R.C.; SILVA, D.F. et al. Estimativa de populações canina e felina domiciliadas em zona urbana do Estado de São Paulo. Rev. Saúde Pública. v. 38, p. 565-570, 2004.

DRISCOLL, C.A.; MCDONALD, D.W.; O'BRIEN, S.J. From wild animals to domestic pets, an evolutionary view of domestication. PNAS, v. 106, n. 1, p. 9971-9978, 2009.

ELLIS, L.S.H.; RODAN, I.; CARNEY, H.C. et al. Feline Environmental Needs Guidelines. Journal of Feline Medicine and Surgery, v. 15, n. 3, p. 219-230, 2013.

FARIA, J.A.; ALVES, N.D.; FILHO, E.F.N. et al. Os animais, cães e gatos, no meio urbano e o problema ambiental. In: SEABRA, G. Qualidade de Vida, Mobilidade e Segurança nas Cidades. v. 3. Ed. João Pessoa, PB - Editora Universitária da UFPB, p. 130-141, 2013.

LINSEELE, V.; VAN NEER, W.; HENDRICKX, S. Evidence for early cat taming in Egypt. Journal of Archaeological Science, v. 34, n. 12, p. 2081-2090, 2007. 
MACHADO, J.C.; PAIXÃO, R.L. A representação do gato doméstico em diferentes contextos socioculturais e as conexões com a ética animal. R. Inter. Interdisc. INTERthesis, v. 11, n. 1, p. 231-253, 2014.

MAgnabosco, C. População domiciliada de cães e gatos em São Paulo: perfil obtido através de um inquérito domiciliar multicêntrico. Dissertação (Mestrado) - Faculdade de Saúde Pública - Universidade de São Paulo, São Paulo, 110 p. 2006.

MARTINS, C.S.; VIANA, J.A. Toxoplasmose - o que todo profissional de saúde deve saber. Clínica Veterinária, v. 3, n. 15, p. 33-37, 1998.

MEDEIROS, R.J., MONTEIRO, F.O.; SILVA, G.C. et al. Casos de intoxicações exógenas em cães e gatos atendidos na Faculdade de Veterinária da Universidade Federal Fluminense durante o período de 2002 a 2008. Ciência Rural, v. 39, n. 7, p. 2105-2110, 2009.

MERK, M.D. Veterinary Forensics: Animal cruelty investigations. Oxford: Wiley-Blackwell, 2013.

OLIVEIRA, V. L.; PIMENTEL, D.; VIEIRA, M. J. O uso do termo de consentimento livre e esclarecido na prática médica. Revista Bioética, v. 18, n. 3, p. 705-24, 2010.

OSÓRIO, A. Alguns aspectos simbólicos acerca do gato. Ilha, v. 12, n. 2, p.232-259, 2011.

PEREIRA, N.; WENDT, S.B.T. Terceira idade e o bem estar animal. ÁGORA, revista de divulgação científica, v. 16, n. 2(A), Número Especial: I Seminário Integrado de Pesquisa e Extensão Universitária, p. 211-215, 2009.

SILVESTRE, A.L. Análise de dados e estatística descritiva. Ed. Escolar, Lisboa - Portugal, 352 p., 2007.

SIQUEIRA, A., CASSIANO, F.C.; LANDI, M.F.A. et al. Non-accidental injuries found in necropsies of domestic cats: a review of 191 cases. Journal of Feline Medicine and Surgery, v. 14, n. 10, p. 723-728, 2012.

SIQUEIRA, A.N.; AUCIELLO, F.S.; BARBOSA, M.E. et al. Lesões não acidentais em gatos: estudo de 90 necropsias relativas a traumas produzidos por energia de ordem mecânica. Archives of Veterinary Science, v. 18, n. 3, p. 361-363, 2013.

THOMAS, K. O homem e o mundo natural: mudanças na atitude em relação às plantas e aos animais (1500-1800). São Paulo: Companhia das Letras, 1988, 544 p.

XAVIER, F.G.; RIGHI, D.A; FLÓRIO, J.C. et al. Cromatografia em camada delgada para o diagnóstico da intoxicação por aldicarb ("chumbinho") em cães e gatos. Arquivo brasileiro de medicina veterinária e zootecnia, v. 59, n.5, p.1231-1235, 2007. 